\title{
SISTEM PENDUKUNG KEPUTUSAN PEMILIHAN MAHASISWA PENERIMA BEASISWA DENGAN K-NN DAN ELECTRE
}

\author{
Deny Nugroho Triwibowo ${ }^{1}$, Ahmad Kurniadi ${ }^{2}$, Siti Hartinah ${ }^{3}$ \\ Magister Teknik Informatika, Universitas Amikom Yogyakarta 1, 2,3 \\ Email : deny.15@students.amikom.ac.id¹,ahmad.kurniadi@students.amikom.ac.id², \\ siti.1148@students.amikom.ac.id ${ }^{3}$
}

\begin{abstract}
ABSTRAK
Beasiswa merupakan salah satu yang merangsang siswa untuk pengingkatan prestasi belajar. Namun, kenyataannya banyak pelajar berprestasi yang ingin melanjutkan pendidikan terhalang akan biaya yang harus dikeluarkan. Sejauh ini Pemerintah dan pihak swasta telah berupaya membantu pelajar - pelajar yang kurang mampu dengan program beasiswa yang diberikan. Akan tetapi, seringkali mengalami masalah dalam menentukan siapa saja siswa yang tepat menerima beasiswa karena setiap siswa mempunyai karakteristik maupun latar belakang yang berbeda-beda yang akan digunakan sebagai acuan pertimbangan dalam menentukan beasiswa. Sehingga diperlukan sebuah sistem pendukung keputusan yang berguna untuk melakukan perangkingan siapa saja pelajar yang berhak menerima beasiswa. Adapun metode yang digunakan dalam melakukan klasifikasi data siswa yang berprestasi menggunakan K-NN dan metode yang digunakan untuk perangkingan hasil klasifikasi K-NN menggunakan ELECTRE. Hasil perhitungan yang dilakukan, dari 12 mahasiswa yang masuk ke dalam klasifikasi mahasiswa berprestasi, setelah dilakukan perankingan hanya 2 mahasiswa yang memiliki nilai tertinggi untuk mahasiswa yang berprestasi dan kurang mampu untuk mendapatkan beasiswa.
\end{abstract}

Kata Kunci: Beasiswa, ELECTRE, K-Nearest Neighbor, Sistem Pendukung Keputusan

\begin{abstract}
Scholarship is one that stimulates students to increase learning achievement. However, in reality many outstanding students who want to continue their education are hindered by the costs. So far the Government and the private sector have sought to help underprivileged students with the scholarship programs provided. However, often have problems in determining who the right students receive scholarships because each student has different characteristics and backgrounds that will be used as a reference consideration in determining scholarships. So we need a decision support system that is useful for ranking who are entitled to receive scholarships. The method used in classifying student achievement data using $K$-NN and the method used for ranking $K$-NN classification results using ELECTRE. The results of calculations performed, of the 12 students who entered into the classification of outstanding students, after ranking only 2 students who had the highest score for students who excel and are less able to get scholarships.
\end{abstract}

Keywords: Scholarship, ELECTRE, K-Nearest Neighbor, Decision Support System 


\section{PENDAHULUAN}

Pada saat ini, pendidikan merupakan hal yang sangat penting bagi setiap orang. Menyadari bahwa pendidikan itu sangat penting, maka dibutuhkannya suatu dukungan. Salah satunya adalah Beasiswa. Beasiswa adalah pemberian berupa bantuan keuangan yang diberikan kepada perorangan, mahasiswa atau pelajar yang digunakan demi keberlangsungan pendidikan yang ditempuh. Biaya tersebut diberikan kepada yang berhak menerima sesuai dengan kriteria yang ditentukan guna meningkatkan motivasi belajar para siswa. Namun, kenyataannya banyak warga negara belum dapat mengenyam pendidikan pada tingkat dasar, lebih-lebih sampai pendidikan perguruan tinggi. Banyak komentar yang disuarakan masyarakat tentang ketidakberdayaan orang tua dalam menyekolahkan anaknya karena terkendala oleh biaya pendidikan yang mahal.

Sejauh ini pemerintah telah berupaya untuk mengurangi angka putus sekolah bagi setiap pelajar yang berprestasi tinggi dengan alasan ekonomi. Untuk menghindari masalah tersebut langkah strategis yang diambil oleh pemerintah adalah memberikan bantuan biaya pendidikan berupa pemberian beasiswa. Sekalipun usaha ini belum dapat menjangkau setiap pelajar di seluruh pelosok Nusantara, tetapi diharapkan dapat memperkecil angka kegagalan studi dengan alasan ekonomi. Keberhasilan dari bantuan beasiswa kepada pelajar bukan diukur dari terserapnya dana yang telah dialokasikan, melainkan dilihat dari tercapainya bantuan pembiayaan studi itu bagi pelajar yang betul-betul memerlukan. Pada gilirannya dapat dilihat adanya kemanfaatan dari pemberian beasiswa itu, sehingga prestasi akademiknya terus meningkat.

Konsep penelitian dengan algoritma $K$ nearest neighbor telah banyak dilakukan oleh peneliti - peneliti sebelumnya diantaranya yaitu, k-nearest neighbor merupakan teknik yang sangat sederhana, efisien dan efektif dalam bidang pengenalan pola, kategori teks, pengolahan objek dan lain-lain, karena kesederhanaan pengolahannya dan mampu melakukan training data dalam jumlah yang besar (Bathia, 2010). Salah satu masalah dari algoritma ini adalah efek yang sama dari semua atribut yang terdapat pada data baru dan data lama dalam dataset pelatihan (Moradian dan Baraani, 2009). K-nearest neighbor mampu melakukan training pada dataset penyakit diabetes untuk melihat dampak negatif hilangnya nilai imputasi dan solusi untuk penyembuhan. Akurasi algoritma k-nearest Neighbor diatas rata rata (Christobel et al., 2013). K-nearest neighbor yang diterapkan pada data konsumen yang menggunakan jasa keuangan kredit kendaraan bermotor, pada penelitian ini $k$-nearest neighbor digunakan untuk penentuan resiko kredit kendaraan bermotor (Leidiyana, 2013).

Penelitian yang dilakukan oleh Ludfiyatul Qoiriyah dkk (2019), menghasilkan kesimpulan bahwa Metode K-Nearest Neighbor (KNN) merupakan sebuah metode yang mengklasifikasikan data dan memiliki konsistensi yang kuat dengan melakukan klasifikasi berdasarkan menghitung kedekatan jarak antara kasus baru dengan kasus lama. Sistem menghasilkan hasil penentuan jenis beasiswa berdasarkan kriterian yang telah ditentukan, yaitu IPK, semester, penghasilan dan tanggungan orang tua. 
Berdasarkan hasil pengujian user acceptance test yang dilakukan, dapat diambil kesimpulan bahwa penerapan metode K-Nearest Neighbor (KNN) untuk menentukan jenis beasiswa memberikan hasil yang diharapkan dan diterima dengan baik dengan presentase hingga $86 \%$. Sistem Pendukung Keputusan Penentuan Jenis Beasiswa menggunakan metode K-NN selanjutnya dapat dilakukan penelitian lebih lanjut dalam penentuan nilai $\mathrm{K}$ agar memperoleh nilai $\mathrm{K}$ terbaik yang akan digunakan dalam proses pengklasifikasian. Selain itu, perlu adanya pengembangan untuk kriteria-keteria yang sifatnya sulit terukur seperti kriteria semester.

Oleh karena itu, maka penulis sangat tertarik untuk mengkaji sistem pendukung keputusan penerimaan beasiswa terhadap mahasiswa yang berprestasi, namun mahasiswa tersebut memiliki keterbatasan dari segi financial. Penggabungan metode K-NN dan ELECTRE di dalam system pendukung keputusan untuk menentukan penentuan penerima beasiswa. Disini metode K-NN nantinya akan digunkan untuk memprediksi mahasiswa berprestasi dan metode ELECTRE untuk melakukan perangkingan sebagai hasil pendukung keputusan.

\section{LANDASAN TEORI}

\subsection{K-NN}

Menurut Han dan Kamber (2006), KNearest Neighbor (K-NN) adalah suatu metode yang menggunakan algoritma supervised dimana hasil dari query instance yang baru diklasifikan berdasarkan mayoritas dari kategori pada K-NN. Tujuan dari algoritma ini adalah mengklasifikasikan obyek baru berdasarkan atribut dan training sample.
Classifier tidak menggunakan model apapun untuk dicocokkan dan hanya berdasarkan pada memori. Diberikan titik query akan ditemukan sejumlah $\mathrm{k}$ obyek atau (titik training) yang paling dekat dengan titik query. Klasifikasi menggunakan voting terbanyak di antara klasifikasi dari k obyek. Algoritma K-NN menggunakan klasifikasi ketetanggaan sebagai nilai prediksi dari query instance yang baru.

Algoritma metode K-NN sangatlah sederhana, bekerja berdasarkan jarak terpendek dari query instance ke training sample untuk menentukan K-NNnya(Amra \& Maghari, 2017). Training sample diproyeksikan ke ruang berdimensi banyak, dimana masing-masing dimensi merepresentasikan fitur dari data.Ruang ini dibagi menjadi bagian-bagian berdasarkan klasifikasi training sample. Sebuah titik pada ruang ini ditandai kelas c jika kelas c merupakan klasifikasi yang paling banyak ditemui pada $\mathrm{k}$ buah tetangga terdekat dari titik tersebut. Dekat atau jauhnya tetangga biasanya dihitung berdasarkan Euclidean Distance yang direpresentasikan pada persamaan 1 sebagai berikut:

$D(a, b)=\sqrt{\sum_{k=1}^{d}\left(a_{k}-b_{k}\right)^{2}}$

dimana matriks $\mathrm{D}(\mathrm{a}, \mathrm{b})$ adalah jarak skalar dari kedua vector $a$ dan $b$ dari matriks dengan ukuran d dimensi.

\subsection{ELECTRE}

Electre adalah singkatan dari Elimination Et Choix Traduisant la Realite atau dalam Bahasa inggris berarti Elimination and Choice Expressing Reality. Menurut Janko dan Bernoider (2005), Electre merupakan salah satu 
metode pengambilan keputusan multikriteria berdasarkan pada konsep outranking dengan menggunakan perbandingan berpasangan dari alternarifalternatif berdasarkan setiap kriteria yang sesuai.

Flowchart jalannya metode Electre dapat dilihat pada Gambar 1. Pada awal proses ELECTRE hal yang dilakukan adalah memasukkan seluruh data sekolah yang digunakan dan telah disesuaikan dengan kriteria yang telah dimasukkan oleh pengguna. Kemudian, setelah data sekolah telah dimasukkan, dilakukan proses perhitungan electre, yaitu mulai dari normalisasi matriks keputusan, pembobotan normalisasi matriks keputusan, menentukan himpunan concordance dan discordance, menghitung matriks concordance dan discordance, menghitung matriks domain concordance dan discordance, menghitung aggregate dominance matriks, dan yang terkahir adalah melakukan eliminasi alternatif yang less favourable. Setelah proses ELECTRE telah dilakukan, hasil keluaran proses ELECTRE adalah sekolah yang masuk rekomendasi berdasarakan kriteria yang telah diinputkan oleh pengguna.

Gambar 1 menggambarkan flowchart dari algoritma electre. Dimana dimulai dengan menginputkan data mahasiswa kedalam matrik keputusan. Berikutnya dilanjutkan kedalam normalisasi matrik keputusan, dan dilanjutkan kedalam pembobotan normalisasi matrik keputusan dimana data mahasiswa akan mendapatkan bobot tiap masing-masing data. Berikutnya masuk ketahap penentuan concordanse dan discordanse. Setelah ditentukan masuk ketahapan menghitung matrik domain. Jika telah mendapatkan nilai dari pehitungan akan masuk kedalam penentuan aggregate dominance matrik. Keputusan akhir berupa mahasiswa yang mendapatkan beasiswa berdasarkan rekomendasi.

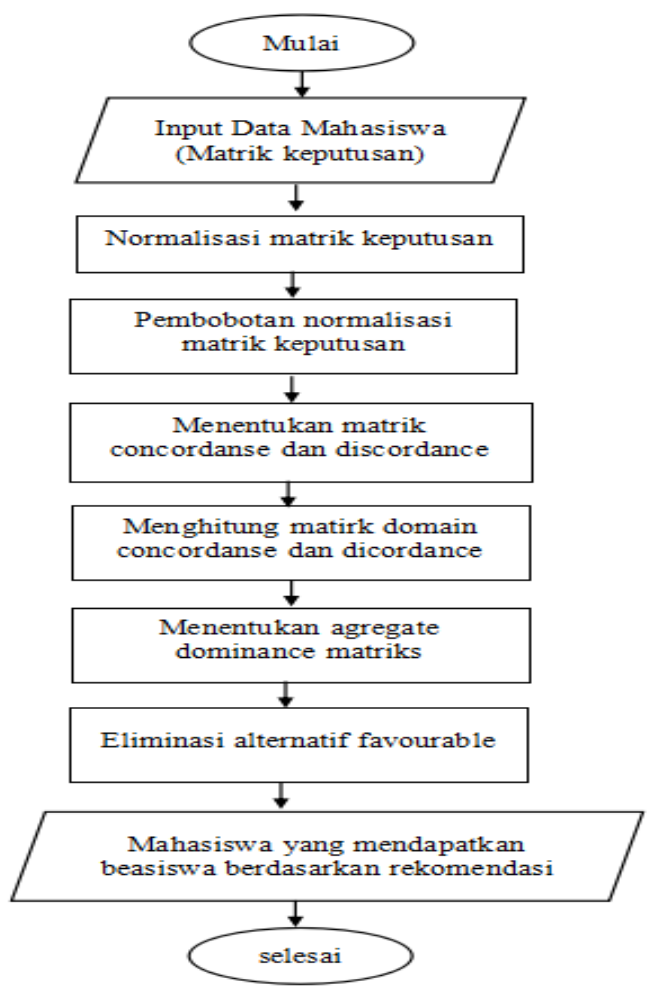

Gambar 1. Flowchart Algoritma ELECTRE

\section{METODE PENELITIAN}

Adapun metode penelitian yang akan dilakukan akan ditunjukkan pada Gambar 2

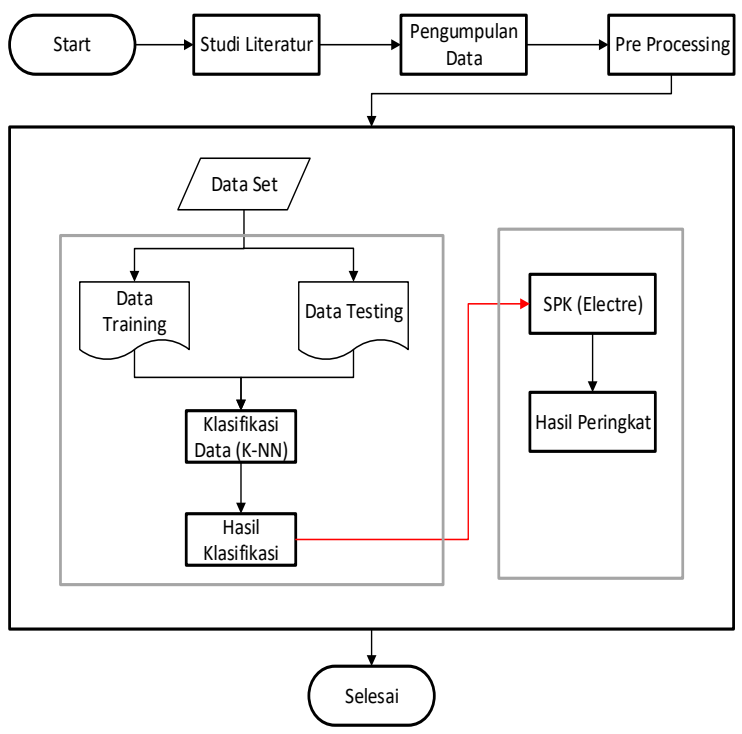

Gambar 2. Flowchart Metode Penelitian 
Penjelasan dari diagram alir penelitian adalah sebagai berikut:

1. Studi literatur: menjelaskan dasar teori yang berkaitan dengan kebutuhan penelitian yang terdapat teori-teori pendukung yang digunakan.

2. Pengumpulan data: Data yang digunakan merupakan data yang bersifat primer yang dikarenakan data yang ada berdasarkan nilai IPK, jumlah karya tulis ilmiah yang telah dibuat, jumlah seminar yang pernah diikuti. Data ini berkaitan dalam penentuan mahasiswa berprestasi. Sedangkan data yang digunakan untuk penetuan kurang mampu berdasarkan jumlah pendapatan orang tua, jumlah pembayaran kuliah, jumlah tanggungan keluarga, dan hasil dari penetuan mahasiswa berprestasi.

3. Proses preprocessing mempunyai tujuan agar data yang digunakan memiliki dimensi yang lebih kecil dan lebih terstruktur, sehingga dapat diolah lebih lanjut.

4. Analisis dan Perancangan Sistem: menjelaskan tentang apa saja kebutuhan sistemyang diperlukan untukmengimplementasikan sistem penentuan penerimaan siswa baru dengan metode K- Nearest Neighbor- ELECTRE.

5. Implementasi: menjelaskan implementasi dari penelitian ini sesuai dengan perancangan pembuatan antarmuka hingga keluaran.

6. Pengujian Sistem: menjelaskan pengujian yang dilakukan untuk mendapatkan akurasi sistem yang telah dibuat.akurasi sistem yang telah dibuat.

\section{HASIL DAN PEMBAHASAN}

Penelitian yang telah dilakukan, menghasilkan aplikasi sistem pendukung keputusan dalam pemilihan mahasiswa penerima beasiswa menggunakan metode K-NN dan Electre.

Untuk perhitungan manual menggunakan metode K-NN dan electre akan diuraikan dalam tahap-tahap berikut:

\subsection{Perhitungan K-NN}

Langkah - langkah perhitungan pada sistem pendukung keputusan penentuan jenis beasiswa menggunakan metode KNN ini adalah sebagai berikut:

Tabel 1. Data Training

\begin{tabular}{clcccc}
\hline No & Nama & IPK & Seminar & KTI & Beasiswa \\
\hline $\mathbf{1}$ & Budi & 3,5 & 4 & 3 & PPA \\
$\mathbf{2}$ & Deny & 3,7 & 3 & 4 & PPA \\
$\mathbf{3}$ & Faisal & 3,4 & 3 & 3 & BIDIK MISI \\
$\mathbf{4}$ & Fauzan & 3,5 & 5 & 2 & PPA \\
$\mathbf{5}$ & Wahyu & 3,6 & 3 & 3 & PPA \\
$\mathbf{6}$ & Sumardi & 3,5 & 1 & 1 & BIDIK MISI \\
$\mathbf{7}$ & Bayu & 3,8 & 2 & 4 & PPA \\
$\mathbf{8}$ & Rendy & 3,6 & 3 & 4 & PPA \\
$\mathbf{9}$ & Yayu & 3,4 & 2 & 1 & BIDIK MISI \\
$\mathbf{1 0}$ & Iman & 3,3 & 3 & 4 & BIDIK MISI \\
$\mathbf{1 1}$ & Khaidir & 3,7 & 2 & 3 & PPA \\
$\mathbf{1 2}$ & Ramli & 3,6 & 4 & 3 & PPA \\
$\mathbf{1 3}$ & Fera & 3,5 & 3 & 4 & PPA \\
$\mathbf{1 4}$ & Dendi & 3,7 & 5 & 3 & PPA \\
$\mathbf{1 5}$ & Gusti & 3,5 & 4 & 2 & PPA \\
$\mathbf{1 6}$ & Hanih & 3,5 & 3 & 3 & BIDIK MISI \\
\hline
\end{tabular}

Dalam penelitian ini ada 20 data sebagai data training dan 20 data sebagai data sampel serta menggunakan $\mathrm{K}=3$ untuk menentukan banyaknya tetangga terdekat. Tabel 3 merupakan pemaparan data sampel pengajuan beasiswa: 
Tabel 2 Data Sampel

\begin{tabular}{clcccc}
\hline No & Nama Siswa & IPK & SEM & KTI & Label \\
\hline $\mathbf{1}$ & Andini & 3,3 & 4 & 3 & $?$ \\
$\mathbf{2}$ & Bayyinah & 3,5 & 3 & 3 & $?$ \\
$\mathbf{3}$ & Della Destylawati & 3,4 & 3 & 4 & $?$ \\
$\mathbf{4}$ & Fitrotus Kholifah & 3,3 & 4 & 5 & $?$ \\
$\mathbf{5}$ & Darwati & 3,7 & 4 & 4 & $?$ \\
$\mathbf{6}$ & Chintia Wiguna & 3,6 & 3 & 3 & $?$ \\
$\mathbf{7}$ & Ali Alifan & 3,5 & 5 & 5 & $?$ \\
$\mathbf{8}$ & Andri Prasetyo & 3,2 & 4 & 3 & $?$ \\
$\mathbf{9}$ & Dodik Andrianto & 3,8 & 3 & 3 & $?$ \\
$\mathbf{1 0}$ & Fauziah & 3,5 & 2 & 5 & $?$ \\
$\mathbf{1 1}$ & Rendi Kurnia & 3,4 & 4 & 2 & $?$ \\
$\mathbf{1 2}$ & Frisya Septifiani & 3,6 & 5 & 4 & $?$ \\
$\mathbf{1 3}$ & Ahmad Adzkiya & 3,5 & 3 & 4 & $?$ \\
$\mathbf{1 4}$ & Rizky Rachmadani & 3,7 & 4 & 3 & $?$ \\
$\mathbf{1 5}$ & Fitri Nur K & 3,6 & 5 & 5 & $?$ \\
$\mathbf{1 6}$ & Elsa Kartika & 3,3 & 3 & 4 & $?$ \\
$\mathbf{1 7}$ & Wardha & 3,8 & 4 & 3 & $?$ \\
$\mathbf{1 8}$ & Agus & 3,9 & 2 & 2 & $?$ \\
$\mathbf{1 9}$ & Yulianawati & 3,6 & 3 & 3 & $?$ \\
$\mathbf{2 0}$ & Mayang & 3,7 & 4 & 5 & $?$ \\
\hline & & & & &
\end{tabular}

Kemudian membandingkan setiap data sampel dengan data training untuk menghiutng jarak terdekat dengan menggunakan ruumus Euclidean distance sebagai berikut:

Tabel 3 Data Normalisasi

\begin{tabular}{clcccc}
\hline No & Nama Siswa & IPK & SEM & KTI & Jarak \\
\hline $\mathbf{1}$ & Andini & 3,3 & 4 & 3 & 0,04 \\
$\mathbf{2}$ & Bayyinah & 3,5 & 3 & 3 & 2,16 \\
$\mathbf{3}$ & Della Destylawati & 3,4 & 3 & 4 & 1,01 \\
$\mathbf{4}$ & Fitrotus Kholifah & 3,3 & 4 & 5 & 2,04 \\
$\mathbf{5}$ & Darwati & 3,7 & 4 & 4 & 1,09 \\
$\mathbf{6}$ & Chintia Wiguna & 3,6 & 3 & 3 & 1,01 \\
$\mathbf{7}$ & Ali Alifan & 3,5 & 5 & 5 & 5,25 \\
$\mathbf{8}$ & Andri Prasetyo & 3,2 & 4 & 3 & 2,09 \\
$\mathbf{9}$ & Dodik Andrianto & 3,8 & 3 & 3 & 8,01 \\
$\mathbf{1 0}$ & Fauziah & 3,5 & 2 & 5 & 2 \\
$\mathbf{1 1}$ & Rendi Kurnia & 3,4 & 4 & 2 & 4,16 \\
$\mathbf{1 2}$ & Frisya Septifiani & 3,6 & 5 & 4 & 0,09 \\
$\mathbf{1 3}$ & Ahmad Adzkiya & 3,5 & 3 & 4 & 2,04 \\
$\mathbf{1 4}$ & Rizky Rachmadani & 3,7 & 4 & 3 & 1,16 \\
$\mathbf{1 5}$ & Fitri Nur K & 3,6 & 5 & 5 & 1,04 \\
$\mathbf{1 6}$ & Elsa Kartika & 3,3 & 3 & 4 & $\mathbf{1 , 0 4}$ \\
$\mathbf{1 7}$ & Wardha & 3,8 & 4 & 3 & $\mathbf{8 , 0 1}$ \\
$\mathbf{1 8}$ & Agus & 3,9 & 2 & 2 & $\mathbf{8 , 0 5}$ \\
$\mathbf{1 9}$ & Yulianawati & 3,6 & 3 & 3 & $\mathbf{0 , 0 9}$ \\
$\mathbf{2 0}$ & Mayang & 3,7 & 4 & 5 & $\mathbf{1 , 1 6}$ \\
\hline & & & & & \\
\hline
\end{tabular}

Hasil pengklasifikasian jenis beasiswa diperoleh setelah melakukan pengurutan jarak dimana jarak terkecil merupakan jarak paling dekat. Data kategori mayoritas yang muncul akan dijadikan sebagai kategori terpilih, hasil pengklasifikasian tersebut seperti pada tabel 4:

Tabel 4 Hasil Akhir lanjut ke Tahap Electre

\begin{tabular}{clcccc}
\hline No & Nama Siswa & IPK & SEM & KTI & Label \\
\hline $\mathbf{1}$ & Andini & 3,3 & 4 & 3 & Ya \\
$\mathbf{2}$ & Darwati & 3,7 & 4 & 4 & Ya \\
$\mathbf{3}$ & Ali Alifan & 3,5 & 5 & 5 & Ya \\
$\mathbf{4}$ & Andri Prasetyo & 3,2 & 4 & 3 & Ya \\
$\mathbf{5}$ & Fauziah & 3,5 & 2 & 5 & Ya \\
$\mathbf{6}$ & Rendi Kurnia & 3,4 & 4 & 2 & Ya \\
$\mathbf{7}$ & Frisya Septifiani & 3,6 & 5 & 4 & Ya \\
$\mathbf{8}$ & Ahmad Adzkiya & 3,5 & 3 & 4 & Ya \\
$\mathbf{9}$ & Rizky Rachmadani & 3,7 & 4 & 3 & Ya \\
$\mathbf{1 0}$ & Fitri Nur K. & 3,6 & 5 & 5 & Ya \\
$\mathbf{1 1}$ & Wardha & 3,8 & 4 & 3 & Ya \\
$\mathbf{1 2}$ & Mayang & 3,7 & 4 & 5 & Ya \\
\hline
\end{tabular}

\subsection{Perhitungan Electre}

Setelah mendapatkan siswa yang sesuai lulus maka disni untuk melihat perankingan dari siswa yang mendaftar peneliti menggunakan metode electre untuk perankingan nya. Di electre dilakukan pembobotan kriteria.

Pembobotan kriteria dilakukan untuk menentukan nilai mutlak dari bobot masing - masing kriteria sehingga dapat diasimiliasi dengan mudah ke dalam metode electre.

Selanjutnya melakukan normalisasi matrik keputusan Normalisasi ini menggunakan Persamaan (2). 
$r_{i j}=\frac{x_{i j}}{\sqrt{\sum_{i=1}^{m} x^{2} i j}}$

Untuk

$i=1,2,3, \ldots, m$ dan

$j=1,2,3, \ldots, n$

Dari rumus diatas, diperoleh hasil normalisasi matrik keputusan berikut ini:

Tabel 5 Normalisasi Data

\begin{tabular}{llll}
\hline 0.127 & 0.309426 & 0.441942 & 0.288675 \\
0.381 & 0.412568 & 0.353553 & 0.288675 \\
0.127 & 0.206284 & 0.176777 & 0.288675 \\
0.254 & 0.309426 & 0.088388 & 0.288675 \\
0.508001 & 0.103142 & 0.265165 & 0.288675 \\
$\mathbf{r}=0.254$ & 0.412568 & 0.441942 & 0.288675 \\
0.381 & 0.309426 & 0.265165 & 0.288675 \\
0.254 & 0.206284 & 0.176777 & 0.288675 \\
0.127 & 0.309426 & 0.353553 & 0.288675 \\
0.381 & 0.412568 & 0.176777 & 0.288675 \\
0.127 & 0.103142 & 0.353553 & 0.288675 \\
0.127 & 0.206284 & 0.265165 & 0.288675 \\
\hline
\end{tabular}

Pada bagian ini, dilakukan pembobotan terhadap matriks hasil normalisasi dari proses sebelumnya menggunakan bobot pengambilan keputusan. Pembobotan ini dilakukan dengan menggunakan Persamaan (3).

$v_{i j}=r_{i j} * w_{j}$

Dari rumus di atas, diperoleh matriks hasil pembobotan sebagai berikut:

Tabel 6 Pembobotan Data

\begin{tabular}{llll}
\hline 0.381 & 0.928279 & 1.325825 & 0.57735 \\
1.143001 & 1.237705 & 1.06066 & 0.57735 \\
0.381 & 0.618853 & 0.53033 & 0.57735 \\
0.762001 & 0.928279 & 0.265165 & 0.57735 \\
1.524002 & 0.309426 & 0.795495 & 0.57735 \\
$\mathbf{v}=.762001$ & 1.237705 & 1.325825 & 0.57735 \\
1.143001 & 0.928279 & 0.795495 & 0.57735 \\
0.762001 & 0.618853 & 0.53033 & 0.57735 \\
0.381 & 0.928279 & 1.06066 & 0.57735 \\
1.143001 & 1.237705 & 0.53033 & 0.57735 \\
0.381 & 0.309426 & 1.06066 & 0.57735 \\
0.381 & 0.618853 & 0.795495 & 0.57735 \\
\hline
\end{tabular}

Selanjutnya menentukan himpunan concordance, dengan membandingkan nilai pada matriks hasil pembobotan berdasarkan Persamaan (4).

$c_{k l}=\left\{j, v_{k j} \geq v_{l j}\right\}$

Untuk

$j=1,2,3,4$

selanjutnya menentukan himpunan discordance, dengan membandingkan nilai pada matriks hasil pembobotan berdasarkan Persamaan (5)

$d_{k l}=\left\{j, v_{k j} \leq v_{l j}\right\}$

Untuk

$j=1,2,3,4$

Langkah berikutnya menghitung matriks condordance berdasarkan himpunan concordance yang diperoleh dari proses sebelumnya. Adapun persamaan yang digunakan untuk menghitung matriks concordance berdasarkan Persamaan (6)

$c_{k l}=\sum_{c}^{j} w_{j}$

Dari rumus perhitungan matriks concordance di atas, diperoleh matriks concordance sebagai berikut:

Tabel 7 Nilai Concordance

\begin{tabular}{cccccccccccc}
\hline- & 5 & 11 & 8 & 8 & 5 & 8 & 8 & 8 & 5 & 8 & 8 \\
8 & - & 11 & 11 & 8 & 8 & 11 & 11 & 11 & 11 & 11 & 11 \\
2 & 2 & - & 5 & 5 & 2 & 2 & 8 & 5 & 5 & 8 & 8 \\
5 & 2 & 8 & - & 5 & 5 & 5 & 8 & 8 & 2 & 8 & 8 \\
5 & 5 & 8 & 8 & - & 5 & 8 & 8 & 5 & 8 & 8 & 8 \\
8 & 5 & 11 & 8 & 8 & - & 8 & 11 & 11 & 8 & 11 & 11 \\
5 & 2 & 11 & 8 & 5 & 5 & - & 11 & 8 & 8 & 8 & 11 \\
5 & 2 & 5 & 5 & 5 & 2 & 2 & - & 5 & 5 & 8 & 8 \\
5 & 2 & 5 & 5 & 8 & 2 & 5 & 8 & - & 5 & 11 & 11 \\
8 & 2 & 8 & 11 & 5 & 5 & 5 & 8 & 8 & - & 8 & 8 \\
5 & 2 & 5 & 5 & 5 & 2 & 5 & 5 & 2 & 5 & - & 8 \\
5 & 2 & 5 & 5 & 5 & 2 & 2 & 5 & 2 & 5 & 5 & -
\end{tabular}


Lanjut dengan menghitung matriks disconcordance dengan persamaan (6)

$d_{k l}=\frac{M A X\left\{\left|v_{k j}-v_{l j}\right|\right\}_{j \in d_{k l}}}{\operatorname{MAX}\left\{\left|v_{k j}-v_{l j}\right|\right\}_{\nabla j}}$

Dimana $j=1,2,3,4, .$.

Dari rumus perhitungan matriks concordance di atas, diperoleh matriks concordance sebagai berikut:

Tabel 8 Nilai Discordance

\begin{tabular}{llllllll}
\hline- & 1 & 0 & 0.36 & 1 & 1 & 1 & 0.48 \\
0.35 & - & 0 & 0 & 0.41 & 0.7 & 0 & 0 \\
1 & 1 & - & 1 & 1 & 1 & 1 & 0.39 \\
1 & 1 & 0.7 & - & 1 & 1 & 1 & 0.86 \\
0.54 & 1 & 0.27 & 0.81 & - & 1 & 1 & 0.41 \\
0 & 1 & 0 & 0.16 & 0.82 & - & 0.72 & 0 \\
1 & 1 & 0 & 0 & 0.62 & 1 & - & 0 \\
0.48 & 1 & 0 & 1 & 1 & 1 & 1 & - \\
\hline
\end{tabular}

Pada bagian ini, dihitung nilai matriks dominan concordance berdasarkan matriks concordance yang diperoleh dari proses sebelumnya. Adapun persyaratan yang digunakan dalam menghitung nilai matriks dominan concordance dengan persamaan (7).

$f=1$, untuk $c_{k l} \geq c$

$f=0$, untuk $c_{k l}<c$

Di mana c merupakan nilai threshold yang diperoleh dari persamaan (8).

$c=\sum c_{k l} /(m(m-1))$

untuk

$k=1,2,3,4$;

$l=1,2,3,4$, dan

$m=$ jumlah calon penerima beasiswa
Dari rumus perbandingan di atas, diperoleh matriks dominan concordance sebagai berikut:

Tabel 9 Matriks Dominan Concordance

\begin{tabular}{cccccccccccc}
\hline- & 0 & 1 & 1 & 1 & 0 & 1 & 1 & 1 & 0 & 1 & 1 \\
1 & - & 1 & 1 & 1 & 1 & 1 & 1 & 1 & 1 & 1 & 1 \\
0 & 0 & - & 0 & 0 & 0 & 0 & 1 & 0 & 0 & 1 & 1 \\
0 & 0 & 1 & - & 0 & 0 & 0 & 1 & 1 & 0 & 1 & 1 \\
0 & 0 & 1 & 1 & - & 0 & 1 & 1 & 0 & 1 & 1 & 1 \\
1 & 0 & 1 & 1 & 1 & - & 1 & 1 & 1 & 1 & 1 & 1 \\
0 & 0 & 1 & 1 & 0 & 0 & - & 1 & 1 & 1 & 1 & 1 \\
0 & 0 & 0 & 0 & 0 & 0 & 0 & - & 0 & 0 & 1 & 1 \\
0 & 0 & 0 & 0 & 1 & 0 & 0 & 1 & - & 0 & 1 & 1 \\
1 & 0 & 1 & 1 & 0 & 0 & 0 & 1 & 1 & - & 1 & 1 \\
0 & 0 & 0 & 0 & 0 & 0 & 0 & 0 & 0 & 0 & - & 1 \\
0 & 0 & 0 & 0 & 0 & 0 & 0 & 0 & 0 & 0 & 0 & - \\
\hline
\end{tabular}

Pada bagian ini, dihitung nilai matriks dominan discordance berdasarkan matriks discordance yang diperoleh dari proses sebelumnya. Adapun persyaratan yang digunakan dalam menghitung nilai matriks dominan discordance dengan persamaan (9).

$g=1$, untuk $d_{k l} \geq d$

$g=0$, untuk $d_{k l}<d$

Dimana $d$ merupakan nilai threshold yang diperoleh dari persamaan (10).

$d=\sum d_{k l} /(m(m-1))$

untuk

$k=1,2,3,4$;

$l=1,2,3,4$, dan

$m=$ jumlah calon penerima beasiswa

Dari rumus perbandingan di atas, diperoleh matriks dominan disconcordance sebagai berikut: 
Tabel 10 Matriks Dominan Discordance

\begin{tabular}{cccccccccccc}
\hline- & 1 & 0 & 1 & 1 & 1 & 1 & 1 & 0 & 1 & 0 & 0 \\
1 & - & 0 & 0 & 1 & 1 & 0 & 0 & 0 & 0 & 0 & 0 \\
1 & 1 & - & 1 & 1 & 1 & 1 & 1 & 1 & 1 & 1 & 1 \\
1 & 1 & 1 & - & 1 & 1 & 1 & 1 & 1 & 1 & 1 & 1 \\
1 & 1 & 1 & 1 & - & 1 & 1 & 1 & 1 & 1 & 1 & 1 \\
0 & 1 & 0 & 1 & 1 & - & 1 & 0 & 0 & 1 & 0 & 0 \\
1 & 1 & 0 & 0 & 1 & 1 & & 0 & 1 & 1 & 1 & 0 \\
1 & 1 & 0 & 1 & 1 & 1 & 1 & & 1 & 1 & 1 & 1 \\
0 & 1 & 0 & 1 & 1 & 1 & 1 & 1 & & 1 & 0 & 0 \\
1 & 1 & 0 & 0 & 1 & 1 & 1 & 0 & 1 & & 1 & 1 \\
1 & 1 & 1 & 1 & 1 & 1 & 1 & 1 & 1 & 1 & & 1 \\
1 & 1 & 0 & 1 & 1 & 1 & 1 & 1 & 1 & 1 & 1 & \\
\hline
\end{tabular}

Menentukan aggregate dominance matrix Pada bagian ini, dilakukan perkalian antara nilai $f$ dan nilai $g$ untuk masingmasing nilai concordance dan disconcordance, sehingga menghasilkan nilai aggregate dominance matrix. Adapun nilai aggregate dominance matrik yang diperoleh adalah sebagai berikut:

Tabel 11 Matriks Aggregate Dominan

\begin{tabular}{ccccccccccccc}
\hline- & 0 & 0 & 1 & 1 & 0 & 1 & 1 & 0 & 0 & 0 & 0 & 4 \\
1 & - & 0 & 0 & 1 & 1 & 0 & 0 & 0 & 0 & 0 & 0 & 3 \\
0 & 0 & - & 0 & 0 & 0 & 0 & 1 & 0 & 0 & 1 & 1 & 3 \\
0 & 0 & 1 & - & 0 & 0 & 0 & 1 & 1 & 0 & 1 & 1 & 5 \\
0 & 0 & 1 & 1 & - & 0 & 1 & 1 & 0 & 1 & 1 & 1 & 7 \\
0 & 0 & 0 & 1 & 1 & - & 1 & 0 & 0 & 1 & 0 & 0 & 4 \\
0 & 0 & 0 & 0 & 0 & 0 & - & 0 & 1 & 1 & 1 & 0 & 3 \\
0 & 0 & 0 & 0 & 0 & 0 & 0 & - & 0 & 0 & 1 & 1 & 2 \\
0 & 0 & 0 & 0 & 1 & 0 & 0 & 1 & - & 0 & 0 & 0 & 2 \\
1 & 0 & 0 & 0 & 0 & 0 & 0 & 0 & 1 & - & 1 & 1 & 4 \\
0 & 0 & 0 & 0 & 0 & 0 & 0 & 0 & 0 & 0 & - & 1 & 1 \\
0 & 0 & 0 & 0 & 0 & 0 & 0 & 0 & 0 & 0 & 0 & - & 0 \\
\hline
\end{tabular}

Hasil akhir di Electre disini yakni dengan Eliminasi alternatif less favourable Pada bagian ini, dilakukan eliminasi terhadap alternatif yang memiliki nilai 1 paling sedikit pada aggregate dominance matrix. Hasil dari eliminasi ini adalah menampilkan alternatif dengan nilai 1 terbanyak pada aggregate dominance matrix. Dari proses perhitungan aggregate dominance matrix sebelumnya, terlihat bahwa alternatif baris ke 4 dan ke 5 memiliki nilai 1 yang lebih banyak daripada alternatif lainnya. Dengan demikian, alternatif keputusan 2 teratas merupakan hasil keputusan dari metode ELECTRE, yang mana mahasiswa bernama Andri Prasetyo dan Fauziah (Tabel 4) menjadi keputusan penerima beasiswa berdasarkan kriteria dan alternatif yang memungkinkan.

\section{SIMPULAN DAN SARAN}

5.1.Kesimpulan

Berdasarkan pada hasil implementasi, pengujian, dan analisis yang telah dilakukan, maka dapat disimpulkan sebagai berikut, Penerapan metode K-Nearest Neighbor dan ELECTRE dalam sistem pendukung keputusan penentuan penerimaan beasiswa mahasiswa berprestasi dan tidak mampu di mulai dari memasukkan data siswa, lalu melakukan klasifikasi predikat menggunakan K-NN terhadap beberapa siswa berprestasi melalui pelatihan, dengan cara mengambil 2 teratas jarak terdekat/tetangganya dari 1 data uji terhadap data latih, sehingga 1 data uji akan mengikuti mayoritas 2 data teratas. Kemudian siswa yang berprestasi akan dilakukan perankingan dengan metode ELECTRE, dengan cara menjumlahkan bobot yang terpenuhi dari kriteria yang telah di-inputkan, lalu mengurutkan nilai bobot terbanyak sehingga sistem akan melakukan perangkingan dan mendapatkan hasil keputusan. 


\subsection{Saran}

Adapun saran yang dari penelitian ini, yaitu :

1. Untuk penelitian lebih lanjut tentang pengembangan dapat dilakukan dengan menambahkan beberapa variable atau kriteria terkait penentuan mahasiswa berprestasi dan kriteria mahasiswa kurang mampu guna mendapatkan hasil yang lebih baik

2. Menambahkan beberapa pengembangan sistem seperti grafik data sehingga lebih mudah dalam membaca data.

\section{DAFTAR PUSTAKA}

Amra, I. A. A., \& Maghari, A. Y. (2017, May). Students performance prediction using $\mathrm{KNN}$ and Naïve Bayesian. In 2017 8th International Conference on Information Technology (ICIT) (pp. 909-913). IEEE.

Bhatia, N. (2010). Survey of nearest neighbor techniques. arXiv preprint arXiv:1007.0085.

Christobel, Y. A., \& Sivaprakasam, P. (2013). A new classwise $\mathrm{k}$ nearest neighbor (CKNN) method for the classification of diabetes dataset. International Journal of Engineering and Advanced Technology, 2(3), 396200.

Han, J., Pei, J., \& Kamber, M. (2011). Data mining: concepts and techniques. Elsevier.

Wijianto, V. M. A. (2018). Comparison Methods of ELECTRE and Simple Additive Weighting (SAW) Methods in Determining the Best Employees of Reward Recipients.

Sugiyarti, E., Jasmi, K. A., Basiron, B., Huda, M., Shankar, K., \& Maseleno,
A. (2018). Decision support system of scholarship grantee selection using data mining. International Journal of Pure and Applied Mathematics, 119(15), 2239-2249.

Qoiriyah, L., Purwanto, H. L., \& Setiyaningsih, W. (2019). Rancang Bangun Sistem Pendukung Keputusan Penentuan Jenis Beasiswa Menggunakan Knn. RAINSTEK: Jurnal Terapan Sains \& Teknologi, 1(2), 64-72.

Sulistyo, D., \& Winiarti, S. (2015). Pemanfatan Informasi Teknologi Dalam Penentuan Beasiswa Siswa Kurang Mampu. Jurnal Informatika Ahmad Dahlan, 9(1), 102213.

Tasril, V. (2018). Sistem Pendukung Keputusan Pemilihan Penerimaan Beasiswa Berprestasi Menggunakan Metode Elimination Et Choix Traduisant La Realite. INTECOMS: Journal of Information Technology and Computer Science, 1(1), 100-109. 